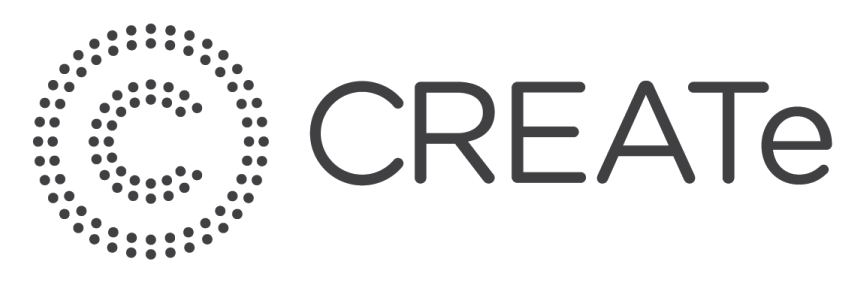

CREATe Working Paper 2018/10 (December 2018)

\title{
Television and the development of the data economy: Data analysis, power and the public interest
}

\author{
Author \\ Gillian Doyle \\ University of Glasgow
}

CREATe Working Paper Series DOI: 10.5281/zenodo.1999430.

This release was supported by the RCUK funded Centre for Copyright and New Business Models in the Creative Economy (CREATe), AHRC Grant Number AH/K000179/1. 


\title{
Television and the
}

development of the data

economy: Data analysis,

power and the public

\section{interest}

\begin{abstract}
Data analysis is steadily becoming more central to management decision-making in media organizations across the globe. The reliance of subscription video on demand $(S V O D)$ services, such as Netflix, on data analytics to underpin decisions about new content investment is well-established. However, what are the key opportunities and challenges facing the rest of the television industry? This article examines how data analysis is facilitating improved methods of personalization and more effective intelligence about the relative appeal of content for differing audience segments. But growing reliance on big data also raises a number of critical public interest questions. This article highlights how data is now a key source of competitive advantage in the television industry and a resource that can be monopolized. It argues that media policy-making needs to pay more attention to the emergence and implications of asymmetries of power in relation to ownership and use of data in managerial decision-making.
\end{abstract}

\section{KEYWORDS}

big data data analysis data regulation algorithms genomes personalization monopolization 
1. Participant observation was carried out at the Data Science in the Entertainment Industries Workshop led by David Boyle, EVP Insight at BBCW in Salford, Manchester on 26 to 27 January 2017 and at the Economics, Law and Policy of Communications and Media Seminar, hosted by FSR Communications \& Media, CMPF and ENTraNCE at EUI, Florence, Italy on 24 to 25 March 2017.

\section{Introduction}

Data analysis is steadily becoming more central to management decisionmaking across the media and in the television industry (Athique 2017; Couldry and Turow 2014). Ongoing increases in the data yielded by online consumption of content provide numerous opportunities for television companies and promise to bring ever-closer alignment between the taste profiles of individuals across the globe and a growing universe of television content properties (Cohn 2016). But capitalizing on such opportunities while safeguarding against threats to competition and to audience welfare calls for a better understanding of the ways that access to data and techniques of data analysis can underpin contemporary decision-making in the television industry.

This article examines how, for major broadcasters and other television content suppliers, analysis of digital data is playing an increasingly central role in providing insights about which properties will appeal to what audience segments and in which territories. The reliance of online Subscription Video on Demand (SVoD) services such as Netflix on data analytics to underpin decisions about new content investment is well established. However, what are the key opportunities and challenges facing the rest of the television industry as digital data analysis moves from the fringes to the forefront in processes of decision-making? Drawing largely on secondary sources (emerging literature, industry reports, and academic and practitioner presentations at recent television industry and policy workshops ${ }^{1}$ ), this article asks how the use of data analysis is being developed by television companies, and it assesses the critical issues raised for public policymakers, focusing particularly on emerging asymmetries of power and information.

\section{From fringes to foreground}

The television industry is beset by many changes at present and whereas, historically, power has tended to reside principally at the distribution end of the supply chain, now, because of the rise of web-connected globalized delivery formats and platforms and because of heightened competition in the distribution stage, the emphasis on vertical cross-ownership of distribution plus content has increased, as evidenced by many recent takeovers (Esser 2016; Doyle 2017). But harnessing the power of big data has become a key driver of patterns of investment and of structural configurations in the television industry too. Indeed, some argue that, for media businesses, having access to data is now just as important as owning content and/or distribution (Arsenault 2017).

While the challenges of transitioning from broadcasting to digital multiplatform content delivery are manifold, one major beneficial by-product of digital distribution for television companies has been the introduction of return path data. Every viewing event on web-connected platforms creates data that can be analysed (Pennington 2017). And as distribution of media content has migrated to web-connected platforms and devices, media suppliers have become increasingly focused on harnessing the value of digital traces left by consumption of that content (Napoli 2014).

Recognition of the impact that big data is having on businesses and society has impressed itself on recent academic literature. Studies from information management and business studies have sought to illuminate how, across many sectors of the economy, big data and advances in data analytics are reshaping business models and employment (Loebbecke and Picot 2015) and offering companies opportunities to profit (Schweidel 2015). In studies 
of management of media, the 'algorithmic turn' has stimulated work on how companies can use digital data to better manage their interactions with audiences and to derive new revenue streams. For example, Evens and Van Damme (2016) have highlighted how news organizations can profit from audiences' willingness to relinquish personal data in return for access to content, thus enabling a diversification away from traditional sources of advertising income which have been in decline.

A number of earlier academic studies have traced the rise of 'algorithmic culture' in the television industry (Cohn 2016). Much work has focused on how big data has transformed audience research (Athique 2017). Some has examined, for example, how the information that emerges from measuring television audience engagement on digital platforms differs from traditional television ratings (Kosterich 2016). Many studies have examined the development and implications of systems of recommendation and, in particular, Netflix's algorithm-based approach (Hallinan and Striphas 2016). However, as Napoli argues, relatively little research has been produced so far 'exploring how big data are being utilized in the management of media organisations' (2016: 3). This article extends knowledge by examining current areas of investment in data analysis by UK broadcasters.

The potential for big data to generate insights about what audiences like is of central interest to television companies. It is well known that production of cultural outputs and especially television content involves high costs and risks while, at the same time, 'nobody knows' what will succeed with audiences (Caves 2000). This state of affairs has encouraged a long history of attempts to quantify likely success factors for cultural outputs. For example, earlier research has attempted to quantify the impact of different cinematic components on a film's subsequent critical and/or box office success (Simonton 2011; Ginsburgh and Weyers 2014). The arrival of the Internet has greatly helped such research by placing in the public domain large amounts of data about the characteristics and performance of cultural outputs. For example, the Internet Movie Database (IMDb) is an online database that provides information about films, television programmes and video games, including about their cast and production crews plus user reviews. Recent exploratory research at the University of Warwick suggests that the success of a television programme may be inferred with reasonably high levels of accuracy from analysis of data readily available on IMDb about a small number of key traits, namely: genre, country of origin and patterns of release (Parry et al. 2017).

Thus, data analysis, traditionally regarded with some wariness in the television industry and confined to Information Technology (IT) departments, has stepped out of its silo and into the mainstream of management decisionmaking. However, this development poses new challenges for media companies and for consumers and public policymakers.

One such challenge is how the endemic organizational culture of some media companies remains resistant to the integration of data specialists, even though the need to bring IT and digital knowhow into strategic decision-making may be well recognized (Doyle 2015). Another strong challenge is that of calculating how to use data judiciously in everyday management decision-making and how to avoid 'editing by numbers' (Doyle, 2015: 57). In the television industry, the question of how far algorithms should be allowed to guide content recommendation systems has received considerable attention (Calvado 2017). While the speed and accuracy of computers in processing large datasets makes reliance on algorithms tempting, the evidence of earlier 
research highlights the dangers of sidelining human judgment entirely in favour of computational methods (Lewis et al. 2013: 49). And a further challenge for media organizations is how to evolve systems of data management that comply with relevant legal frameworks which, in some cases at least - e.g. in the European Union which is transitioning to the General Data Protection Regulation in May 2018 (Bourreau et al. 2017) - are undergoing change in response to public concerns about the potentially harmful implications of large-scale data mining.

The use of data by media companies is, of course, nothing new but digitization has fuelled a significant rise in reliance on data analysis to personalize media content offerings and to inform content investment decisions. Although Cohn (2016: 678) cautions that 'the role that users have in reading and decoding the culture around them' should not be under-estimated, the extent to which consumers are fully aware of how their everyday activities online leave behind digital traces and how these are used by digital content service providers, marketers or others is debatable. While data analysis and use of algorithms are associated with a number of benefits for users, especially lower transaction costs, fewer information problems and speedier decisions, it also raises a number of welfare concerns related to privacy, surveillance and pluralism (Rubinfield and Gal 2016; Kennedy and Moss 2015).

Albeit that, as Athique points out, 'those outraged by the privacy implications of what is essentially a world-spanning phone tap operation are commonly reminded of the old adage: "If its free then you're the product"' (2017: 5), the hidden costs of supposedly free goods may not always be apparent to consumers. From the perspective of public policy-making, weighing up the benefits of effective targeting and lower prices for online services against the adverse effects of loss of privacy and/or the nuisance of intrusive advertisements involve trade-offs that are complex (Bourreau et al. 2017).

Some critics also point to the effects that personalization may have on shared public discourse. Couldry and Turow (2014) argue that the advertising industry's use of big data to target advertising, through fuelling more personalized content, is fracturing audiences and eroding shared civic culture. A growing reliance on big data analysis is, they argue, 'clearing' the landscape of one of the basic ingredients of democratic life: the reliable and regular exchange of common ideas, facts, and reference points about matters of common concern' (Couldry and Turow 2014: 1722).

While the increasingly prevalent use of data does clearly raises a number of critical public interest questions, particularly surrounding privacy, this article argues that a further pressing issue which deserves more recognition than it has received to date is the emergence and implications of asymmetries of power in relation to ownership and use of big data in media decision-making.

\section{Uses of data analysis}

Because we have a direct relationship with consumers, we know what people like to watch and that helps us understand how big the interest is going to be for a given show [...] like House of Cards

(Friedland, Chief Comms Officer of Netflix cited in Carr 2013)

Whereas SVoD services such as Netflix have led the way in using data analysis to assess the likely audience reception for new television shows, now the television industry as a whole is following suit by seeking to harness data in order 
to inform content decisions (Observation, Salford: 26 January, 2017). This is evidenced by the way that, for example in the United Kingdom, broadcasters have moved towards making registration compulsory for viewers in order to access online catch-up services (Clark 2017). Registration means providing at least some basic personal information that enriches the data about individual viewing experiences that the broadcaster can collect and use. In the commercial sector, mainstream free-to-air services such as ITV and Channel Four already require registration before giving access to their on-demand services ITV Hub and All 4 On Demand, respectively. In announcing its plans to made registration compulsory for users of the iPlayer from 2017, the BBC made clear that this would benefit audiences by facilitating more personalization. According to Director General Tony Hall:

I want everyone to get the very best from the BBC. By learning about what you want and like we can take you to more of the great programmes you love, stories you might be interested in and content you might otherwise never have discovered.

(Hall, cited in Ling 2016)

Across the board, it is evident that not only maturing SVoD platforms but also traditional television broadcasters with their well-stocked catch-up services are focused on how best to use data analysis to enable viewers to make better informed choices. Since abundance is an intrinsic feature of digital on-demand services, the appeal of any offering depends not only on having content that audiences like but also on providing navigation tools that make choices manageable (Calvado 2017). For many on-demand content services, the use of recommendation systems - which typically are based on analysing data about the sort of content that users with similar taste patterns have chosen in the past in order to predict material that a current user will like - provide a solution. As broadcasters evolve their on-demand content services, the development of data-informed systems of profiling that facilitate processes of navigation and selection through personalized recommendations and tailored homepages has become a priority (Observation, Salford: 26 January 2017).

This approach underpins, for example, Spotify's Discover Weekly, a tool that uses algorithms in order to provide service users with a new personalized playlist every week based on analysis of the consumption behaviours of others with similar tastes (Observation, Salford: 26 January 2017). The development of a personalized playlist, whereby'millions of people [are] treated as uniques as opposed to millions of people being treated as one of many' (Page, cited in Simms 2016), was a major innovation as a curation tool when it was launched in July 2015, and many Spotify subscribers are now habituated users of this facility according to Spotify's Director of Economics Will Page (Observation, Salford: 26 January 2017).

The challenges for on-demand services that offer audio-visual content as opposed to music are distinct because of immense difference in the relative sizes of television versus music catalogues, differing arrangements with copyright owners and because of the contrasting ways that music listeners, as opposed to television viewers, select and consume content. But, even so, it is conceivable that, as data about individual viewing choices becomes more abundant over time, television content providers may eventually emulate Spotify in drawing on collaborative filtering to offer a bespoke individualized curatorial service to users of their content archives. 
At present however, navigation and cross-promotion of television content are centred around recommendation systems and most if not all broadcasters are investing in improving the accuracy of these (Observation, Salford: 26 January 2017). A key challenge television service providers face is the tradeoff between, broadly, algorithmically based filtering systems that are relatively low cost versus more complex and tailored ones that require more human curatorial input. According to Greg Detre, Chief Data Scientist at Channel Four, while automated recommendation systems will often come up with suggestions that audiences find suitable, they are generally weighted towards 'raw popularity' (Detre 2017). However, broadcasters' needs for a more refined means of targeting and developing audiences is propelling new investment into research and development of increasingly sophisticated filtering systems based not only on automated metrics but also on human editorial input (Detre 2017; Observation, Salford: 26 January 2017).

Several US and UK broadcasters have gone beyond investing purely in recommendation engines to, in addition, creating systems of analysing data that help with predicting which forms of content will have appeal and for whom (Observation, Salford: 26 January 2017). For many, this involves developing 'genomes' whereby content is broken down or classified into very detailed categories (such as the production location or the mood of the script) so that how attractive each constituent component is for differing audience segments can then be subjected to close analysis (ibid). This may involve, as a starting point, testing viewer responses to content and applying predictive analytics and multiple regression models to tease out which of the component characteristics of television programmes tend to engender the strongest reactions from audiences (Barsotti 2017).

The ability to harness data analysis in order to predict what sort of content will appeal to which audience segments and in which territories has increased enormously in the digital era thanks to not only the availability of massive amounts of audience data but also on account of the rise of automated systems for identifying and classifying content by traits (Observation, Salford: 26 January 2017). A number of broadcasters are currently working on developing automated systems whereby machine readings of synopses and descriptions of television programmes provide a basis for assigning items of content with hundreds of contextual attributes, for example: genre and subgenre; nationality of actors; location; mood of the plot; whether music plays an important role in driving the narrative, etc. (Danaher, cited in Barsotti 2017). Armed with a detailed 'genome' for each title in their portfolio, owners of television content portfolios can then tease out recurrent trends in relation to what sort of content has appeal and for whom.

This approach follows in the footsteps of earlier work in the music industry, such as Music Genome Project, which involves analysing and classifying songs according to a framework of hundreds of attributes in order to identify traits that are popular and to find and recommend works that contain similar elements (Kumar et al. 2016). At the forefront of such approaches in the context of the television industry is BBC Worldwide, the commercial arm of the BBC, where the Insight Team, led by David Boyle, is developing the use of genomes and predictive analysis in order to help forecast which BBCW content properties are likely to appeal in differing international markets (Boyle 2016). According to Boyle,'data helps the BBC determine which countries a new show is best suited for - and which shortform content will be most engaging in promoting those shows' (ibid). The 
$\mathrm{BBC}$ is far from alone in seeking to develop systems for classifying and coding content according to a myriad of traits in order to then predict their likely appeal for differing audience segments - commercial players such as Sky in the United Kingdom and HBO and Disney in the United States have also been investing in developing systems that more effectively optimize the match between their content, audiences and advertisers. Strategic takeovers offer an effective means of procuring specialist capability rapidly, as evidenced by, for example, the acquisition by Hulu (owned by NBC Universal, Disney and Fox) of Video Genome Project (VGP) in December 2016 (Goikhman 2017; Spangler 2016) or by Sky's investment in technology companies such as DataXu (McDonald 2016).

Thus, in the television industry, the race is on to develop the most effective systems of anatomizing and classifying content in such a way as maximizes its predictive value. Harnessing big data in this way provides value to television companies by (1) yielding insights about the relative appeal of content which, in turn, may help to inform pricing and sales negotiations surrounding finished product; and (2) offering intelligence as to what sorts of content are worth investing in the first place - a benefit that SVoD services such as Netflix already exploit to evident advantage.

\section{The development of the data economy and the public interest}

While the ways that big data can inform and facilitate decision-making undoubtedly promise benefits for the television industry and for audiences, the migration towards greater reliance on data analysis does also raise a number of public interest concerns. In particular, a key concern for policymaking is the emergence and implications of asymmetries of power in relation to ownership and use of data that now represents a key informational resource in the television industry. As is argued below, the growing centrality of data analysis raises other concerns too related to widespread use of personalization techniques and to the future of content investment.

\section{Informational asymmetries and market power}

Whereas in many other sectors of the economy (e.g. insurance) an extensive reliance on statistical analysis to drive business decisions is nothing new, for media, digital distribution has been a catalyst for the inexorable rise of data analysis (Observation, Salford: 26 January 2017). Television executives might have bragged in the past that investment in hit shows was down to 'gut instinct' but, in the digital era, wisdom distilled from big data is unquestionably the aid of choice. Data analysis is also indispensable in strategies of targeting and addressing digital audiences. For media companies, Google's Chief Economist Hal Varian's observation (cited in Lohr 2009) that statistical analysis would be 'the sexy job in the next ten years' has turned out to be highly prescient.

Harnessing data effectively requires investment in such activities as recording, collecting, storing and analysing data to extract value (Mayer-Schonberger and Cukier 2013). In the television industry, broadcasters and other content service providers have made substantial investments in these activities based on the understanding that the recording or creation of datasets simultaneously brings ownership of that data and the right to exploit it. Access, on an exclusive basis, to the valuable information that can be drawn out of proprietorial 
datasets, enables a return on investment to be earned. As Brobst, CEO of data analytics firm Teradata, puts it:

Let's say I'm Netflix and I collect lots of data [...] to provide a service to you, it shouldn't be that my competitors should benefit from all this investment I've made [...] That's my asset.

(Brobst, cited in Wolpe 2015)

In effect, ownership of or access to data and to the techniques needed to make sense of data so as to inform management decision-making are now key sources of competitive advantage in the television industry, and they are resources that can be monopolized.

In drawing attention to the need for competition authorities to take heed of this and head off exclusionary and anti-competitive practices, some have argued that data should be seen as 'the new oil' in the economy (Economist 2017). This analogy is misleading in that, unlike oil, which is a scarce physical commodity, data is intangible, and it is non-rivalrous in that its supply is not diminished through usage (Schepp and Wambach 2016). But data, like oil, constitutes an important input factor to the economy in the digital era. At the same time, data gathering and analysis are characterized by the widespread availability of economies of scale and scope which means that the economics of these activities 'favour market concentration and dominance' (OECD 2014: 7)

In media industries, where the strategic importance of access to relevant data is especially great, the case for regulatory oversight to avoid potentially anti-competitive effects is compelling. As Arsenault suggests, the need for media companies to control specific distribution mechanisms has waned nowadays next to the importance of 'leveraging data to predict which delivery mechanisms work best for which product, at which particular moment' (Arsenault 2017: 20).

Earlier research has, rightly, drawn critical attention to the potent threats to pluralism, democracy and social cohesion posed by unrestrained monopolization in media industries (Freedman 2012; Iosifidis 2011). But monopolization also affects economic efficiency. Monopolization of data militates against the most efficient utilization of what is an 'infrastructural resource' (OECD 2014: 5) which can, theoretically, be re-used by many different companies bringing increasing returns to scale and scope, growth in productivity and resultant broad economic and societal gains. But however strong the efficiency-based arguments against exclusion might be, it is unsurprising that monopolization occurs, given the substantial investments required 'to develop and maintain databases, meta-data and related algorithms' (ibid: 6).

While uneven knowledge amongst competing suppliers about what audiences like is a long-standing fact of life in media markets, the informational asymmetries that have emerged alongside the rise of globalized online distribution have raised concern, not least on account of the growing dominance of a handful of US-based technology-driven players such as Netflix and Amazon, in amassing and drawing value from personal data (McLaughlin 2017). Concerns about monopolization have prompted policymakers in the European Union to question the effects of such dominance in relation both to consumer privacy and to competition and innovation (Van Gorp 2015; Bourreau et al. 2017; De Streel and Herrera-Gonzalez 2017). 
Netflix, which has become an increasingly important commissioning purchaser of original television content, has been criticized for hoarding data and 'refus[ing] to reveal figures on how popular, or not, its shows are' (Sweney 2017). One special concern is the resultant informational asymmetries that may skew negotiations between television service providers (buyers) and producers (sellers) of content to the detriment of the latter. It is well recognized that in order to build their businesses, television producers need to negotiate favourable terms on retention and secondary exploitation of the rights to their content assets. Producers' ability to do this is dependent on the distribution of bargaining power along the vertical supply chain (Doyle 2017: 7) but also, crucially, it rests on producers having information about the popularity of their own shows. Whereas traditionally producers, broadcasters and other distributors have been able to draw on readily available and identical audience data from third-party sources such as BARB or Neilsen, producers whose output is commissioned by SVoD players are now frequently faced with the problem of sparse or non-existent access to information about how their content has fared with audiences.

It is well recognized that informational asymmetries may, at times, result in market failure. Economics Nobel Laureate Akerlof famously used the example of transactions in used cars or 'lemons' to demonstrate how when buyers or sellers do not have the same information this can lead to market failure and to an inefficient use of resources (Akerlof 1970). Likewise if distributors and producers of television content lack correct information about the popularity of specific content propositions then, theoretically, it is more likely that investment in provision of said content will take place at a level that is greater or less than is socially optimal.

But whether, in reality, monopolization of data and related problems of asymmetric information might provide a market-failure-based justification for intervention is debatable (Cowen and Crampton 2002). The relationship between monopoly and technological innovation has never been straightforward. While some economists argue that monopolists hold back rivalry and therefore deter innovation, others adhere to the more Schumpeterian viewpoint that the incentive of being able to reap monopoly profits, at least in the short term, is precisely what encourages firms to make risky investments in new initiatives in the first place (Doyle 2013: 185). Few would deny that those who invest in collecting and analysing data in innovative ways so as to better serve audiences and build their businesses deserve rewards. But that the possibilities for analytics-driven innovation which have excited imaginations right across the television industry can only be realized by those handful of broadcasters and SVoD companies who enjoy access to the de facto means of participation in harnessing digital datasets seems, from a wider societal perspective, somewhat wasteful. Of particular note is the fact that 'independent' television production companies who are not vertically integrated into broadcasting or distribution entities with relevant resources will be left behind in developing and exploiting data-insight-driven approaches to investment in new content. This informational asymmetry exists at the very time when UK and European policymakers are extolling the importance for our creative production sectors of using new technology in order to prosper (Create UK 2014).

\section{Personalization}

Another area of concern surrounding the developing use of data analysis by television companies relates to the widespread collection and use of personal data which has drawn criticisms about privacy and about the effects of an 
ever-growing and pervasive emphasis of personalization. Despite concerns about the implications for privacy of large-scale data mining, it is broadly well recognized that a trade-off exists between privacy and lower prices to the consumer for online services - essentially data disclosures help to pay for content services where otherwise charges would have to be levied on the user (Deutscher 2017; Evens and Van Demme 2016). Likewise with personalization techniques based on algorithmic analysis of personal datasets, while its attendant acquiescence to the creep of robotics (Gal 2017) and its normalization of large-scale data mining (Cohn 2016) may well be concerns, at the core lies a trade off between data disclosure and the benefit of recommendation systems that audiences generally tend to regard as helpful and convenient.

Clearly personalization helps television audiences to navigate vast archives of content. However, as marketing analysts have discovered, '[g]reater personalization typically increases service relevance and customer adoption, but paradoxically, it also may increase customers' sense of vulnerability and [therefore] lower adoption rates' (Aguirre et al. 2015). So for television companies a key challenge is the decision about 'where to draw the line between the usefully personalized and the excessively personal' (Guszeza in Schweidel 2015: xvii). In announcing that registration to use the iPlayer will become compulsory in 2017 as part of a 'reinvention' of PSB for the digital age, Director General Tony Hall argued that ' $[\mathrm{m}]$ illions of people are already benefitting from this more personalized BBC and by rolling it out for everyone no one will be left behind' (cited in Ling 2016). But the BBC has allowed that those registering may forego personalization by adjusting their privacy settings accordingly. Such sensitivity to public ambivalence about data mining and increased levels of surveillance on the part of a publicly funded broadcaster is clearly prudent but not all television services make it so easy to opt out of personalization techniques.

Another peril of recommendation systems is their capacity to ensnare viewers in filter loops and bubbles at the expense of potential for serendipity and taste development. Earlier work has highlighted the dangers of filter bubbles in relation to online news content where, confronted by a multitude of offerings, audiences may end up'dwell[ing] intellectually only in arenas where they are comfortable, creating barriers between them and those in the public sphere with whom they would not likely agree' (Couldry and Turow 2014: 1711). Filter bubbles, as they affect news consumption, are especially worrying because access to an array of political viewpoints is seen as part of the bedrock of democracy. But access to a plurality of entertainment content also matters to individuals and to societal aspirations relating to promotion of tolerance and sociocultural cohesion. So, as television companies invest in the development of algorithmically generated recommendation systems, the knowledge and skills needed to interrogate the design of such systems and to consider, for example, the extent to which algorithms are constructed to achieve easy hits or by contrast to slightly challenge and develop existing taste profiles will become increasingly relevant to the domain of media policy-making.

\section{Implications for local content}

A key focus for investment at present is development of genomes or systems for anatomizing television content in order to better predict its likely appeal in differing markets. As discussed earlier, the application of techniques based on machine reading and categorization of content to create detailed genomes is very much aimed towards understanding the wants and needs of international 
audiences. To the extent that insights gleaned about content that has wide international potential may, over time, increasingly influence content investment decision-making, a correspondingly negative implication for local content is inescapable.

Does it matter if data-informed content investment decisions favour material that is internationally oriented over content that serves the narrower interests of local and national television audiences? Television is widely recognized as a key aspect of the landscape of everyday cultural provision and as a vector through which societal 'values, myths and symbols that serve to unite' are shaped and shared (Smith 1998: 187). As such, the availability of content aimed primarily at local audiences and the potential threat to diversity and societal welfare posed by marginalization of local content are concerns that surface regularly in media and cultural policymaking discourses. Referring to the disruption caused by new digital intermediaries such as Netflix, the Canadian Heritage Minister, Mélanie Joly, recently warned that that' [i]f we're complacent, this new wave of information can drown out our own content our French-language TV and films; our indigenous music; our multicultural programming' (2017).

It is widely recognized that sustaining diversity has become much more difficult with 'the emergence of powerful transnational platforms commercialising cultural goods and services online' (García Leiva and Albornoz 2017: 10). Even so, as is reflected in a plethora of national and international policy initiatives such as the UNESCO Convention on Cultural Diversity, preservation of access to diverse audio-visual outputs, including indigenously made television content, is regarded as essential in promoting social cohesion and integration, in maintaining plurality and democracy and in sustaining regional and national identities and in some cases languages (UNESCO 2005).

The development of profiling techniques to help identify material likely to appeal in international markets has implications not only for content but also for content production. Earlier research has drawn attention to the critical industrial issues surrounding increased reliance on international markets as the primary source of financing for production of screen content (Paterson 2017). Any push towards content that works predominantly for international markets makes it more difficult for programmes geared mainly towards the concerns of domestic audiences to attract production funding (Esser 2016: 3605). So, at stake here is not only the welfare of local audiences but also, potentially, the economic position of local producers in an increasingly globalized television environment.

\section{Conclusions}

The rise of digital distribution has provided television companies with unprecedented levels of data and, in turn, enabled development of improved tools and methods for understanding the tastes, preferences and behaviours of their audiences. For UK broadcasters, a major focus for investment is on improved data-informed systems of profiling to facilitate easier navigation and more effective curation of content (Observation, Salford: 26 January 2017; Pennington 2017). A move by some traditional broadcasters, such as Channel Four, towards blending manual with computational methods reflects the fact that, whereas full automation may be attractive on grounds of cost, the integration of human input that brings contextual sensitivity and rigour alongside machine-based computation is apt to achieve optimal results (Lewis et al. 2013). 
Not only can analysis of online consumption data provide a closer understanding of the taste profiles of audiences at individual and aggregate level, but also, as systems for tagging and coding content become increasingly sophisticated, data analysis can yield ever more detailed insights into the sort of component characteristics of content that are likely to appeal to audiences (Observation, Salford: 26 January 2017; Parry et al. 2017). Another key area for investment by television companies at present, especially for companies such as the $\mathrm{BBC}$ that are major owners of content, is the development of genomes or automated systems of classifying content according to its constituent traits with a view to then teasing out what sorts of content will appeal to which audience segments and in what territories. Thus, lured by the promise of a cornucopia of market intelligence, data analysis has moved from the fringes to the foreground as an area for investment in the television industry.

The migration towards ever-increasing reliance on data analysis has triggered a number of policy concerns, and this article calls for a refocusing of regulatory priorities around use of data. While privacy has been the main focus for intervention to date, this article argues that media policy-making needs to pay more attention to the emergence and implications of asymmetries of power in relation to ownership and use of data which now represents a key informational resource in the television industry.

Earlier research has drawn attention to the' growing significance of data as an input factor and valuable asset' and the need for policymakers to try and ensure that concentrated control over data does not result in market distortions (Schepp and Wambach 2016: 124). This is especially true in the television industry where opportunities to profit, both commercially and creatively, from what Hallinan and Striphas (2016: 117) describe as 'render[ing] algorithmic information processing systems legible as forms of cultural decision making', abound. It is well established that decisions about how data is used can have significant welfare implications (Thornham and Goméz Cruz 2018). So, as well as striving to promote fair competition and efficiency, data-related policy interventions need to reflect additional societal aspirations impinged upon by the use of data in managerial decision-making in the television industry such as diversity and taste development.

However, given the increasing complexity of the globalized digital media distribution ecosystem, policy-making in this area is, as pointed out by the OECD (2014: 7), bedeviled by considerable challenges in relation to defining relevant markets, pinpointing levels of market concentration and quantifying exact welfare implications. Addressing such challenges requires appropriate expertise. Therefore if the public interest is to be safeguarded effectively at the same time as industry strives to harness the advantages of changing technology, it is not only television companies but also media and competition regulators who now need to increase their investment in specialist skills in data analysis suited to the challenges of big data era.

\section{ACKNOWLEDGEMENTS}

The generosity of the organizers of two key events at which participant observation was carried out - the Data Science in the Entertainment Industries workshop held in Manchester on 26 to 27 January 2017 and the Economics, Law and Policy of Communications and Media seminar held at EUI, Florence, Italy on 24 to 25 March 2017 - is very gratefully acknowledged. The support of the UK Economic and Social Research Council (ES/N015258/1) is also gratefully acknowledged. 


\section{REFERENCES}

Aguirre, E., Mahr, D., Grewal, D., de Ruyter, K. and Wetzels, M. (2015), 'Unraveling the personalization paradox: The effect of information collection and trust-building strategies on online advertisement effectiveness', Journal of Retailing, 91:1, pp. 34-49.

Akerlof, G. (1970), "The market for "lemons": Quality uncertainty and the market mechanism', The Quarterly Journal of Economics, 84:3, pp. 488-500.

Arsenault, A. (2017), 'The datafication of media: Big data and the media industries', International Journal of Media and Cultural Politics, 13:1\&2, pp. 7-24.

Athique, A. (2017), 'The dynamics and potentials of big data for audience research', Media, Culture \& Society, 40:1, pp. 59-74.

Barsotti, S. (2017), 'Hold tight and pretend it's a plan: Big Data and BBC's Doctor Who', Carnegie Mellon University News, 21 February, http:// www.heinz.cmu.edu/news/news-detail/index.aspx?nid=3925. Accessed 23 August 2017.

Bourreau, M., de Streel, A. and Graef, I. (2017), Big Data and Competition Policy: Market Power, Personalised Pricing and Advertising, Brussels: Centre on Regulation in Europe (CERRE).

Boyle, D. (2016), 'Catchy content: What makes TV content work?', Strata Data Conference, New York, 27-29 September, https://conferences.oreilly.com/ strata/strata-ny-2016/public/schedule/detail/53526. Accessed 30 July 2017.

Calvado, E. (2017),'Recommender systems:Trust and biased advice', Economics, Law and Policy of Communications and Media, FSR Communications \& Media, CMPF and ENTraNCE Annual Scientific Seminar, Florence: EUI, 24-25 March.

Carr, D. (2013), 'Giving viewers what they want', New York Times, 24 February, http://www.nytimes.com/2013/02/25/business/media/for-house-of-cardsusing-big-data-to-guarantee-its-popularity.html?mcubz=0. Accessed 25 August 2017.

Caves, R. (2000), Creative Industries: Contracts Between Art and Commerce, Cambridge, MA: Harvard University Press.

Clark, L. (2017), 'You'll soon need an account to watch BBC iPlayer', Wired, 11 May, http://www.wired.co.uk/article/bbc-iplayer-to-require-loginfrom-2017. Accessed 23 August 2017.

Cohn, J. (2016), 'My TiVo thinks I'm gay: Algorithmic culture and its discontents', Television and New Media, 17:8, pp. 675-90.

Couldry, N. and Turow, J. (2014), 'Advertising, big data and the clearance of the public realm: Marketers' new approaches to the content subsidy', International Journal of Communication, 8, pp. 1710-26.

Cowen, T. and Crampton, E. (2002), Market Failure or Success: The New Debate, Cheltenham, UK: Edward Elgar Publishing.

Create UK (2014), Creative Industries Strategy, London: Creative Industries Council UK, www.thecreativeindustries.co.uk/media/243587/cic_report_ final-hi-res-.pdf. Accessed 23 August 2017.

Detre, G. (2017), 'Centaur evaluation, combining minds and machines for better recommendations', Presentation at Data Science Conference, Salford: BBC, 26-27 January.

Deutscher, E. (2017), 'The role of personal data and privacy in merger analysis - a critical assessment of the EU Commission's Facebook/WhatsApp decision', Economics, Law and Policy of Communications and Media, FSR Communications \& Media, CMPF and ENTraNCE Annual Scientific Seminar, Florence: EUI, 24-25 March. 
Doyle, G. (2013), Understanding Media Economics, 2nd ed., London: Sage Publications.

(2015), 'Multi-platform media and the miracle of the loaves and fishes', Journal of Media Business Studies, 12:1, pp. 49-65.

- (2017), 'Television production: Configuring for sustainability in the digital era', Media, Culture and Society.

Economist (2017), 'The world's most valuable resource is no longer oil, but data', The Economist, 6 May, http://www.economist.com/news/leaders/ 21721656-data-economy-demands-new-approach-antitrust-rules-worldsmost-valuable-resource. Accessed 28 May 2017.

Esser, A. (2016), 'Challenging US leadership in entertainment industries? The rise and sale of Europe's international TV production groups', International Journal of Communications, 10, pp. 3585-614.

Evens, T. and van Damme, K. (2016), 'Consumers' willingness to share personal data: Implications for newspapers' business models', International Journal on Media Management, 18:1, pp. 25-41.

Freedman, D. (2012), 'Metrics, models and the meaning of media ownership', International Journal of Cultural Policy, 20:2, pp. 1-16.

Gal, M. (2017), 'Algorithmic consumers', Economics, Law and Policy of Communications and Media, FSR Communications \& Media, CMPF and ENTraNCE Annual Scientific Seminar, Florence: EUI, 24-25 March.

García Leiva, M. and Albornoz, A. (2017), 'Cultural industries and diversity: Old debates and new challenges', Quaderns del CAC, 43, pp. 5-15.

Ginsburgh, V. and Weyers, S. (2014), 'Nominees, winners and losers', Journal of Cultural Economics, 38:4, pp. 291-313.

Goikhman, D. (2017), 'How big data will shape the hypercompetitive online video space', CMSwire.com, 20 January, http://www.cmswire.com/digitalexperience/how-big-data-will-shape-the-hypercompetitive-online-videospace/. Accessed 25 August 2017.

Van Gorp, N. (2015), 'Competition among information (digital) platforms: Study for ITRE committee', IP/A/ITRE/2014-11, workshop proceedings, Brussels: European Parliament, 20 January.

Hallinan, B. and Striphas, T. (2016), 'Recommended for you: The Netflix Prize and the production of algorithmic culture', New Media \& Society, 18:1, pp. 117-37.

Iosifidis, P. (2011), Global Media and Communication Policy: An International Perspective, Basingstoke, UK: Palgrave Macmillan.

Joly, M. (2017), 'Launch of Creative Canada', speech by the Minister of Canadian Culture, Ottawa, ON: Economic Club of Canada, 28 September, https://www.canada.ca/en/canadian-heritage/news/2017/09/creative_ canada_-avisionforcanadascreativeindustries.html. Accessed 28 November 2017.

Kennedy, H. and Moss, G. (2015), 'Known or knowing publics? Social media data mining and the question of public agency', Big Data $\mathcal{E}$ Society, 2:2, pp. 1-22.

Kosterich, A. (2016), 'Reconfiguring the "hits": The new portrait of television program success in an era of big data', International Journal on Media Management, 18:1, pp. 43-58.

Kumar, D., Sowmya, B., Chetan, S. and Srinivasa, K. (2016), 'A comparative study of classifiers for music genre classification based on feature extractors', Distributed Computing, VLSI, Electrical Circuits and Robotics (DISCOVER), Mangalore, India: IEEE, pp. 190-94. 
Lewis, S., Zamith, R. and Hermida, A. (2013), 'Content analysis in an era of big data: A hybrid approach to computational and manual methods', Journal of Broadcasting \& Electronic Media, 57:1, pp. 34-52.

Ling, T. (2016), 'You'll need a password to watch BBC iPlayer from 2017', The Radio Times, 27 September, http://www.radiotimes.com/news/2016-0927/youll-need-a-password-to-watch-bbc-iplayer-from-2017. Accessed 21 May 2017.

Loebbecke, C. and Picot, A. (2015),'Reflections on societal and business model transformation arising from digitization and big data analytics: A research agenda', The Journal of Strategic Information Systems, 24:3, pp. 149-57.

Lohr, S. (2009), 'For today's graduate, just one word: Statistics', New York Times, 6 August, http://unionstats.gsu.edu/8220/NYT_Lohr_StatisticsJobs.pdf. Accessed 23 August 2017.

Mayer-Schonberger, V. and Cukier, K. (2013), Big Data: A Revolution That Will Transform How We Live, Work and Think, New York: John Murray Publishers.

McDonald, A. (2016), 'Sky buys into big data business', TBI Vision, 25 January, http://bivision.com/news/2016/01/sky-buys-big-data-business/537682/. Accessed 21 August 2017.

McLaughlin, D. (2017), 'Are Facebook and Google the new monopolies?', Bloomberg, 13 July, https://www.bloomberg.com/news/articles/2017-07-13/ antitrust-built-for-rockefeller-baffled-by-bezos-quicktake-q-a. Accessed 23 August 2017.

Napoli, P. (2014), 'On automation in media industries: Integrating algorithmic media production into media industries scholarship', Media Industries, 1:1, pp. 33-38.

- (2016), 'Special issue introduction: Big data and media management', International Journal on Media Management, 18:1, pp. 1-7.

OECD (2014), Data-Driven Innovation for Growth and Well-Being: Interim Sythesis Report, Paris: OECD, October.

Parry, G., Pogrebna, G. and Del Vecchio, M. (2017), 'The science of nudging viewers using IMDb TV show profiling', presentation, Data Science Conference, Salford, UK: BBC, 26-27 January.

Paterson, R. (2017), 'The competition discourse in British broadcasting policy', CREATe working paper 2017/02, Glasgow, UK: CREATe.

Pennington, A. (2017), 'This time it's personal', Broadcast TECH, London: MBI, February/March, pp. 16-19.

Rubinfield, D. and Gal, M. (2016), 'The hidden costs of free goods: Implications for antitrust enforcement', Antitrust Law Journal, 80:3, pp. 521-62.

Schepp, N. and Wambach, A. (2016), 'On big data and its relevance for market power assessment', Journal of European Competition Law and Practice, 7:2, pp. $120-4$.

Schweidel, D. (2015), Profiting from the Data Economy: Understanding the Roles of Consumers, Innovators and Regulators in a Data-Driven World, Upper Saddle River, NJ: Pearson Education.

Simms, D. (2016), 'The state of music discovery: Why Spotify's discovery weekly is the music industry's greatest innovation of 2015', idobi, 26 April, http://idobi.com/editorial/the-state-of-music-discovery/. Accessed 2 April 2017.

Simonton, D. (2011), Great Flicks: Scientific Studies of Cinematic Creativity and Aesthetics, Oxford, UK: OUP.

Smith, A. (1998), Nationalism and Modernism: A Critical Survey of Recent Theories of Nations and Nationalism, London: Routledge. 
Spangler, T. (2016), 'Hulu acquires video genome project to enhance recommendation for live TV, VOD', Variety, 15 November, http://variety.com/2016/ digital/news/hulu-acquires-video-genome-project-vgp-1201918435/. Accessed 21 August 2017.

De Streel, A and Herrera-González, F. (2017), 'How to integrate zero-priced markets in anti-trust analysis', FSR Communications \& Media, CMPF and ENTraNCE Annual Scientific Seminar, Florence: EUI, 24-25 March.

Sweney, M. (2017), 'Netflix tops $100 \mathrm{~m}$ subscribers as it draws worldwide audience', The Guardian, 18 July, https://www.theguardian.com/media/2017/ jul/18/netflix-tops-100m-subscribers-international-customers-sign-up. Accessed 23 August 2017.

Thornham, H. and Goméz Cruz, E. (2018), 'Not just a number? NEETS, data and datalogical systems', Information, Communication $\mathcal{E}$ Society, 21:2, pp. 206-321.

UNESCO (2005), Convention on the Protection and Promotion of the Diversity of Cultural Expressions, Paris: United Nations Educational, Scientic and Cultural Organization, 20 October.

Webster, J. (2014), The Marketplace of Attention: How Audiences Take Shape in a Digital Age, Cambridge, MA: The MIT Press.

Wolpe, T. (2015), 'Data privacy: You may call it personal data but who actually owns it?', ZDNet, 11 June,http://www.zdnet.com/article/data-privacyyou-may-call-it-personal-data-but-who-actually-owns-it/. Accessed 23 August 2017.

\section{SUGGESTED CITATION}

Doyle, G. (2018), 'Television and the development of the data economy: Data analysis, power and the public interest', International Journal of Digital Television, 9:1, pp. 53-68, doi: 10.1386/jdtv.9.1.53_1

\section{CONTRIBUTOR DETAILS}

Gillian Doyle is professor of media economics and director of the Centre for Cultural Policy Research (CCPR) at the University of Glasgow, where she leads Glasgow's MSc in media management. A former president of the Association for Cultural Economics International (ACEI) and a member of the European Expert Network on Culture and Audiovisual (EENCA), she has conducted studies of economic and policy aspects of media and audio-visual industries for bodies including the OECD and UK Research Councils. Gillian is principal investigator on 'Television Production in Transition: Independence, Scale and Sustainability', funded by the UK Economic \& Social Research Council (ES/ N015258/1).

Contact: Centre for Cultural Policy Research, University of Glasgow, 13 Professor Square, Glasgow G12 8QQ, UK.

E-mail: Gillian.Doyle@Glasgow.ac.uk

Gillian Doyle has asserted her right under the Copyright, Designs and Patents Act, 1988, to be identified as the author of this work in the format that was submitted to Intellect Ltd. 


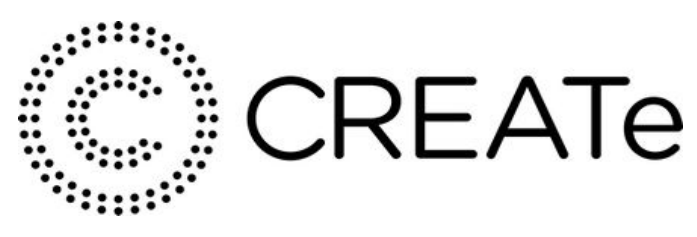

RCUK Centre for Copyright and New Business Models in the Creative Economy

College of Social Sciences / School of Law University of Glasgow

10 The Square

Glasgow G12 8QQ

Web: www.create.ac.uk

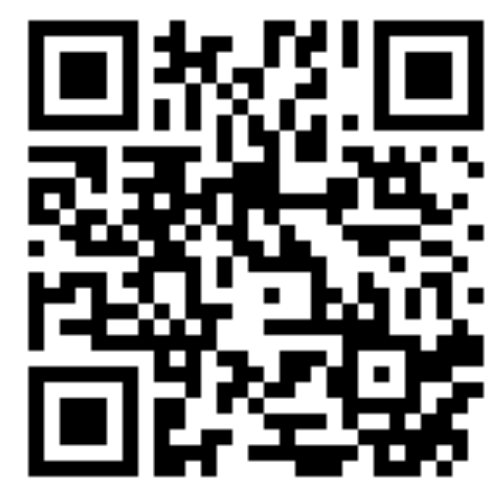

